\title{
8
}
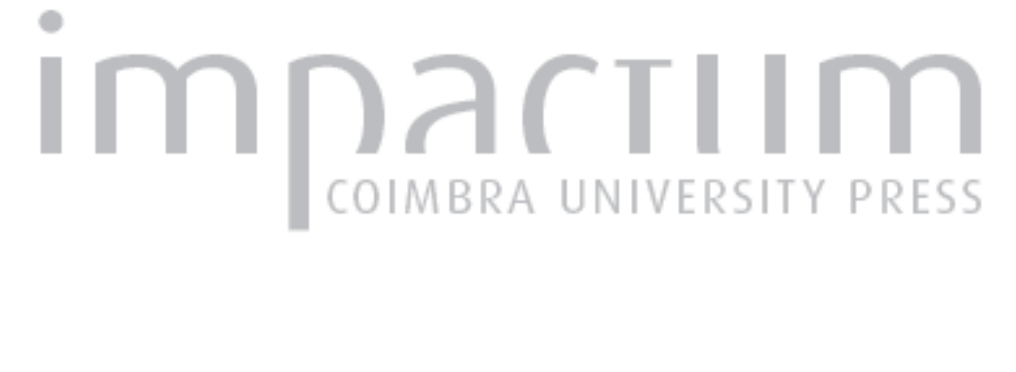

\section{A (cons)ciência regional europeia}

\section{Autor(es): Malginova, Ekaterina}

Publicado por: Centro de Informação Europe Direct de Aveiro; Centro de Estudos \section{Interdisciplinares do Século XX}

URL

persistente:

DOI:

URI:http://hdl.handle.net/10316.2/33992

DOI:http://dx.doi.org/10.14195/1647-6336_11_21

Accessed : $\quad$ 26-Apr-2023 11:48:03

A navegação consulta e descarregamento dos títulos inseridos nas Bibliotecas Digitais UC Digitalis, UC Pombalina e UC Impactum, pressupõem a aceitação plena e sem reservas dos Termos e Condições de Uso destas Bibliotecas Digitais, disponíveis em https://digitalis.uc.pt/pt-pt/termos.

Conforme exposto nos referidos Termos e Condições de Uso, o descarregamento de títulos de acesso restrito requer uma licença válida de autorização devendo o utilizador aceder ao(s) documento(s) a partir de um endereço de IP da instituição detentora da supramencionada licença.

Ao utilizador é apenas permitido o descarregamento para uso pessoal, pelo que o emprego do(s) título(s) descarregado(s) para outro fim, designadamente comercial, carece de autorização do respetivo autor ou editor da obra.

Na medida em que todas as obras da UC Digitalis se encontram protegidas pelo Código do Direito de Autor e Direitos Conexos e demais legislação aplicável, toda a cópia, parcial ou total, deste documento, nos casos em que é legalmente admitida, deverá conter ou fazer-se acompanhar por este aviso.

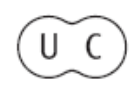


DEBATER

A EUROPA

jul-dez 2014

QUE EUROPA(S)?

CONTEXTOS E DESAFIOS 


\title{
A (cons)ciência regional europeia
}

\author{
Ekaterina Malginova \\ Mestranda em Estudos Europeus da FLUC \\ E-mail: ekaterinamalginova@gmail.com
}

\section{Resumo}

Esta abordagem será centrada na análise do processo de regionalização na União Europeia tendo como exemplo o caso italiano. Examinando as alterações político históricas do país emergiu a necessidade de uma adaptação económica das diferentes zonas da Itália. O aparecimento de regiões veio, por um lado trazer reformas políticoadministrativas e por outro, dúvidas e as mais variadas interpretações quanto ao papel das regiões não só no contexto italiano como também, no quadro da União Europeia. Pretende- se compreender a importância da regionalização e dos investimentos económicos para o desenvolvimento e prosperidade das "regiões europeias".

Palavras Chave: União Europeia; Politica Regional; Cooperação; Regionalização; Itália;

\begin{abstract}
This approach will focus on the analysis of the regionalization process in the European Union illustrating in specific the Italian case. The political and historical changes of the country required adjustment in different areas of Italy. The emergence of regions brought a political-administrative and other reforms, doubts and many different interpretations about the role of regions not only in the Italian context but also within the framework of the European Union. The purpose is to understand the importance of regionalization and of the economic investments for the development and prosperity of the "European regions".
\end{abstract}

Key Words: European Union; Regional Policy; Cooperation; Regionalization; Italy; 
Pensemos a União Europeia a dois níveis. A nível nacional e a nível internacional. Pensemos no euro e na globalização. Não esquecendo, que a condição do nacional implica a noção de uma Europa regionalizada.

A realidade das transformações que ocorrem na União Europeia nos diferentes domínios devem - se, entre outros fatores, aos alargamentos e as adesões dos países (agora) membros da União Europeia, que por sua vez exigiram com que a UE adaptasse o seu funcionamento e a sua estrutura às necessidades dos países que consigo trouxeram realidades e práticas diferentes. O processo de integração (política, económica e regional) e a própria evolução do processo de cooperação nos e entre os Estados Membros visa a coesão e a solidariedade. As diferenças nas proporções geográficas, populacionais e linguísticos suportam a necessidade da existência de objetivos e trajetos comuns dentro da União.

Esta abordagem será centrada na análise do processo de regionalização na União Europeia tendo como o exemplo o caso italiano. Tendo em conta as alterações político históricas do país emergiu a necessidade de uma adaptação económica das diferentes zonas da Itália. O aparecimento de regiões veio, por um lado trazer reformas políticoadministrativas e por outro, dúvidas e as mais variadas interpretações quanto ao papel das regiões não só no contexto italiano como também, no quadro da União Europeia. Pretende- se compreender a importância da regionalização e dos investimentos económicos para o desenvolvimento e prosperidade das "regiões europeias". As transformações neste plano levam- nos a pensar, que contributos por parte da UE e qual é o papel das regiões neste contexto para que o seu desenvolvimento seja espelhado no progresso da União como o templo de um conjunto de regiões desenvolvidas, dotadas de competências e adotadas às suas especificidades que não as tornam superiores ou inferiores em relação às outras regiões. Apenas as distingue.

A proposta da Comissão Europeia, conhecida por “Agenda Europa 2020" consiste num conjunto de iniciativas de prioridade e interesse dos Estados Membros com ações a todos os níveis, organizadas à escala da UE, nacional e autoridades locais e regionais na EU a 28.

No Presente, através de investimentos, a União Europeia tem procurado ajustar as grandes assimetrias vigentes entre as regiões, o caso de Itália é um exemplo de relevante consideração.

Será, por isso, necessário compreender (consciência) uma Europa regionalizada ou instruir (ciência) para uma regionalização europeia? 
Comecemos pela compreensão. O desenvolvimento social e económico, a solidariedade e o reforço da coesão são elementos estruturantes do processo de integração europeia. A sua importância encontra-se expressa, logo na década de 80 . Em particular, na reforma dos Fundos Estruturais, aprovada em 1988, que solicitou uma maior participação do nível regional e local. Do ponto de vista jurídico, estes princípios foram evocados pela primeira vez nas negociações que conduziram ao Ato Único Europeu em 1986 e sucessivamente incluídos ${ }^{1}$ no Tratado de Maastricht em 1992/1993 que previu, entre outras matérias, a estabelecimento ${ }^{2}$ do Comité das Regiões.

A coesão económica e social $^{3}$ exprime a solidariedade entre os EstadosMembros e as regiões da União Europeia sendo essencialmente alcançada através da Política Regional da União Europeia. Favorece o desenvolvimento equilibrado do território comunitário bem como a redução das diferenças estruturais entre as regiões da União. Concretiza-se através de diversas intervenções financeiras, nomeadamente as dos Fundos Estruturais e do Fundo de Coesão.

"A Política Regional da UE é uma política de investimento que apoia a criação de emprego, a competitividade, o crescimento económico, a melhoria da qualidade de vida e o desenvolvimento sustentável, contribuindo assim para a realização dos objetivos da estratégia Europa 2020"4.

Apesar das tentativas de uma equalização na União Europeia, existem grandes diferenças em termos de riqueza.

"Por exemplo, o país mais rico da UE, o Luxemburgo, é sete vezes mais rico do que a Roménia e a Bulgária, que foram os últimos países a aderir à UE e que são também os Estados-Membros mais pobres. Todavia, o efeito de alavanca da adesão à UE, em conjugação com uma política regional eficaz e adaptada a objetivos específicos, pode dar bons resultados"

A crise económica e financeira atual veio agravar as disparidades e as assimetrias de desenvolvimento no interior da União Europeia. Importa sublinhar a importância assumida pelas políticas de coesão económica e social no processo de integração europeia no Passado e Presente para que possamos compreender a necessidade dos seus investimentos no Futuro.

\footnotetext{
${ }^{1} \mathrm{O}$ Tratado de Maastricht institucionalizou depois esta política no Tratado CE (artigos $158 .^{\circ}$ a $162 .^{\circ}$ ).

${ }^{2}$ Ver mais dados relativos à legislação http://eur-lex.europa.eu/pt/legis/latest/chap14.htm.

${ }^{3}$ A nível europeu, a coesão económica e social remonta ao Tratado de Roma (1957), cujo preâmbulo faz alusão à redução das desigualdades de desenvolvimento entre as regiões.

${ }_{5}^{4}$ Confira-se em: http://ec.europa.eu/regional_policy/index_pt.cfm

${ }^{5} \mathrm{http} / / /$ europa.eu/pol/reg/index_pt.htm
} 
No que diz respeito a arquitetura institucional é da responsabilidade do Comité das Regiões ${ }^{6}$, organismo ${ }^{7}$ dentro do funcionamento da União, representar todas as regiões europeias na União Europeia. Dentro do próprio espaço da União visa por sua vez, o relacionamento entre a União e os seus cidadãos.

A legislação ao nível da UE para além da competência da Comissão Europeia, Parlamento e Conselho é o também dos diversos órgãos consultivos (estabelecido no Tratado TFUE) que têm de ser ouvidos sempre que a legislação proposta envolva a sua área de interesse. Ainda que os seus pareceres não sejam aceites, contribuem para a supervisão democrática da legislação da EU.

A "voz do poder local” é de elevada importância no panorama Europeu não só pelo fato de representar as cidades e as regiões europeias mas também porque três quartos da legislação europeia são executados a nível local e regional. A democracia tem assim mais lugar nas regiões, uma vez que existe um maior contexto do europeu no "local" e por isso é de extrema importância o contacto entres os vários níveis.

A título supervisor, o Conselho de Municípios e Regiões da Europa é uma rede de germinações ${ }^{8}$, que assegura que estas beneficiem de um financiamento adequado. Neste contexto são organizados seminários, congressos e publicados estudos. Fazendo-o identificam-se os valores que as geminações encarnam: a amizade, a cooperação e a compreensão entre os povos da Europa. As geminações são a expressão da unidade e da identidade europeias. Representam, sem qualquer dúvida, a forma mais visível de cooperação europeia. Requerem um duplo compromisso: das Autoridades Locais e, dos Cidadãos estando assim obrigados a um contacto direto com estes ${ }^{9}$.

O sistema de financiamento da UE é complexo. Existem muitos tipos de diferentes programas que estão sob a responsabilidade de diversos organismos. Mais de

\footnotetext{
${ }^{6}$ Comité das Regiões, um dos organismos da União Europeia com sede em Bruxelas, Bélgica é responsável pela apresentação do ponto de vista das regiões sobre as propostas da Comissão Europeia. Sendo um órgão consultivo também do Parlamento Europeu e do Conselho tem 353 membros e o mesmo número de suplentes. Após o Tratado de Maastricht 1992/1993 que em 1994 deu origem ao Comité das Regiões o número de membros, segundo os alargamento foi aumentando de 189 para o número de hoje. É constituído por seis comissões que discutem segundo as áreas de divisão os problemas, planos de cada região. Confira-se em: http://europa.eu/about-eu/institutions-bodies/cor/index_pt.htm

${ }^{7}$ Comité Económico e Social Europeu, que representa grupos da sociedade civil, como empregadores, sindicatos e grupos de interesse social; Comité das Regiões, que assegura que a voz do poder local e regional seja ouvida.

8 "As geminações são o encontro de dois municípios que concordam em proclamar que se associam para agirem numa perspetiva europeia, confrontando os seus problemas e desenvolvendo entre eles laços de amizade cada vez mais estreitos". Foi assim que Jean Bareth, um dos fundadores do Conselho dos Municípios e Regiões da Europa (CMRE) definiu as geminações no pós Segunda Guerra Mundial.

${ }^{9}$ Confira-se em: http://www.twinning.org/pt/page/enquadramento-breve.html http://www.twinning.org/pt/page/o-conselho-dos-munic\%C3\%ADpios-e-regi\%C3\%B5es-da-europa.html
} 
$76 \%$ do orçamento europeu é gerido pelos países da UE, nomeadamente os Fundos Estruturais, ao abrigo dos quais são financiados programas regionais. A criação dos Fundos de apoio (FEDER) destinam- se a reforçar a coesão económica e social na União Europeia através da correção dos desequilíbrios regionais. O programa FEDER financia investimentos de vária ordem ${ }^{10}$.

O segundo ponto de partida para a compreensão do fenómeno aqui apresentado passa pela consciência do processo de regionalização como fator político, histórico, fator económico, fator geográfico. Quanto ao fator político: recordemos o Tratado de Paris 1951, Tratado Roma 1957, Ato Único Europeu 1987, Tratado Maastricht 1993 e o Tratado de Lisboa 2009 e a importância que estes tratados tiveram no enquadramento da região e dos conceitos que à esta noção dizem respeito.

Entre os Tratados citados destaca-se o de Lisboa, que sendo o mais recente foi de elevada importância para o debate sobre a regionalização na Europa. Consistiu no reforço do poder das regiões - nos termos do Tratado de Lisboa, "a Comissão Europeia deve consultar as entidades locais e regionais, bem como as respetivas associações de toda a UE, já na fase pré-legislativa. Enquanto representante do ponto de vista das entidades locais e regionais, o Comité das Regiões participa ativamente nesse processo". O funcionamento desse processo é lógico e essencial. Quando a Comissão apresenta uma proposta legislativa, deve consultar novamente o Comité das Regiões se a proposta em causa se referir a um dos domínios de ação que afeta diretamente as entidades locais e regionais.

Existe a necessidade de entender um outro fator. O problema que continua a preocupar a União é a discrepância de pontos de vista a nível nacional e regional. Um dos fatos que foram encontrados no site oficial da União: “o Parlamento nacional não é obrigado a considerar as várias posições das assembleias regionais ou a promover a procura de uma posição comum, dado não existir qualquer obrigatoriedade legal de incluir a sua participação" - pois não tem qualquer obrigatoriedade legal de proceder nesse sentido. O Parlamento nacional informa os Parlamentos regionais relativamente à decisão final. O Tratado de Lisboa veio trazer um elemento crucial a ser desenvolvido

\footnotetext{
${ }^{10}$ Ajudas diretas aos investimentos realizados nas empresas (designadamente as PME), a fim de criar emprego duradouro; Infra estruturas ligadas, nomeadamente, à investigação e à inovação, às telecomunicações, ao ambiente, à energia e aos transportes; Instrumentos financeiros (fundos de capitalrisco, fundos de desenvolvimento local, etc.), a fim de apoiar o desenvolvimento regional e local e favorecer a cooperação entre as cidades e as regiões; Medidas de assistência técnica. O FEDER pode intervir a título dos três novos objetivos da política regional: Convergência Competitividade regional e emprego; Cooperação territorial europeia.
} 
no quadro do mecanismo de alerta precoce e da observância da subsidiariedade. Mas isso é tema para um outro debate.

Observemos o cenário italiano a este prepósito. O território italiano estende- se dos Alpes até ao Mar Mediterrâneo. Composto pelas ilhas de Sicília, Sardenha e Elba, a Península Italiana contém dois pequenos Estados independentes: a Cidade do Vaticano, em Roma, e a República de São Marinho.

“Após a assinatura do Tratado de Roma em 1957, pela Alemanha, Bélgica, França, Itália, o Luxemburgo e os Países Baixos, a Europa construída pelos Estados que tomaram as decisões mais importantes e que decidiram os alargamentos institucionais",

o cenário que se veio a prolongar até aos dias de hoje data de inúmeros projetos de reparos e introduções legislativo - políticos, culturais e económico- socias.

O processo de unificação italiana teve um papel importante na construção da Itália que conhecemos hoje. No início do século XIX, Itália era um conjunto de pequenos Estados submetidos à forças estrangeiras. O movimento de unificação italiana desencadeou-se nos anos 50 do século XVIII e com apoio do movimento "Jovem Itália"12 de G. Mazzini.

Apesar da unificação, as diferenças internas do reino persistiam. A introdução de novas leis pelos liberais que estavam no poder e a falha das reformas agrárias levou a destruição no Sul e ao reforço da zona do Norte. Começou a diferença notória entre o Norte o Sul de Itália. Os políticos em favor de uma descentralização administrativa permaneceram muito tempo destituídas. A lenta democratização ${ }^{13}$, manteve uma parte da população no desconhecimento das leis e no desinteresse dos valores do liberalismo.

A importância da Constituição marcou o novo modelo de pensamento sobre a regionalização na Itália.

Após um referendo em 1946 entrou em vigor em 1948 a Constituição que tornou a Itália numa República Parlamentar. O fim da Segunda Guerra Mundial, a queda do

\footnotetext{
${ }^{11}$ Tradução do autor do trabalho, in KUKAWKA, Pierre (2001) L'Europe par les régions, Presses Universitaires de Grenoble. p.5.

12 Jovem Itália- “Giuseppe Mazzini (1805-1872) no manifesto da sociedade secreta Jovem Itália (Giovine Italia), emitido em 1831, em Marselha, onde estava exilado, dizia que a constituição de unidades nacionais, era o presságio da grande Federação Europeia que deve unir numa só associação todas as famílias do antigo mundo. A federação dos povos livres apagará a divisão dos Estados (...). Por José Adelino Maltez. Confira-se em:

http://www.iscsp.utl.pt/ cepp/teoria_das_relacoes_internacionais/a_jovem_europa_de_mazzini.htm Última consulta em 5.01.2014.

${ }^{13}$ O sufrágio universal foi apenas instaurado em 1912, para os homens.
} 
regime de forte centralização do poder de Mussolini e uma nova Constituição "romperam com a filosofia centralizadora e totalitária do regime fascista" 14.

Face ao número de regiões periféricas e as minorias nacionais, as razões de política interna e internacional, nas quais a República deverá conceder as garantias constitucionais, as regiões deverão ser tomadas em conta. O novo coletivo, a região, nasceu com o artigo $5^{\circ}$ da Constituição.

Não menos importante foi artigo $116 .^{\circ}$ - centésimo décimo sexto, que deu um estatuto especial à cinco regiões ${ }^{15}$. As leis da Constituição vieram para cada uma das cinco regiões respeitando as suas condições especiais de autonomia. Um dos exemplos foi a ilha de Sicília. O Estatuto de $1946{ }^{16}$ fez da Sicília uma região autónoma com uma assembleia deliberativa, um executivo: a junta e um presidente. Trata-se de uma descentralização de "audaciosa", um pouco mais do que a que foi dada às quatro outras regiões do interior. $\mathrm{O}$ uso e o ensino da sua língua minoritária foram também permitidos.

\section{Noção de Estado Regional}

A Forma de Estado italiana compreende o Parlamento, bicameral, que é constituído pelo Senado ${ }^{17}$ ou Câmara Alta, e pela Câmara dos Deputados ${ }^{18}$.

As formas de Estado conduzem à consideração da composição geral do Estado, a estrutura do poder, a sua unidade e a distribuição de competências no território do Estado, neste caso Itália, um Estado regionalizado (menos central).

A definição de Estado Regional pressupõe uma certa autonomia em relação aos poderes que o regem (Legislativo, Executivo e Judiciário). Esta forma de Estado é Unitária e pouco descentralizada, pois este não elimina por completo a superioridade política e jurídica do poder central estando as regiões constitucionalmente submetidas.

\footnotetext{
${ }^{14}$ DEYON, Pierre (1997) Regionalismes et régions dans l'Europe des quinze. Bruxelles, Bryulant. p.71.

${ }^{15}$ Sicília, Sardenha, Trentino-Alto Adige - os alemães representam dois terços da população; Le Val d'Aoste na qual residia a maioria francófona e Frioul- Venétie Julienne.

${ }^{16} \mathrm{O}$ estatuto deu às suas autoridades uma competência exclusiva nos domínios da indústria, do comércio, da agricultura, dos trabalho públicos, da instrução primaria e da polícia local. Uma larga autonomia financeira e uma contribuição do Estado para o desenvolvimento económico da ilha, como a solidariedade e a equalização.

${ }^{17}$ Senato della Repubblica.

${ }^{18}$ Camera dei Deputati.
} 
Assim, o processo de descentralização na União Europeia justifica-se não apenas na progresso da democracia como também na unidade territorial, no caso de Itália isso foi visível.

No contexto de forte desigualdade económica e cultural entre o Norte e o Sul de Itália surgiram os movimentos separatistas que lutaram pela independência do Norte $^{19}$. A alternativa para resolver estas situações foi a de oferecer maior autonomia às regiões (as regiões podem elaborar o seu Estatuto nos limites da Lei nacional). Desta forma, o Estado italiano tem optado por uma descentralização cada vez mais acentuada, fato que prova o caráter descentralizador de Itália.

\section{Estrutura administrativa}

A República Italiana é subdividida, política e administrativamente, segundo um esquema piramidal, que parte do Governo Central até aos municípios.

Dividida em 20 regiões, cinco das quais (Sardenha, Sicília, Trentino-Alto Adige, Vale d'Aosta e Friul-Venezia Giulia) têm como já mencionado, um «estatuto especial». Outras quinze regiões introduzidas mais tarde, Piemonte, Lombardia, Veneto, Ligúria, Emilia-Romagna, Toscana, Umbria, Marche, Abruzzo, Molise, Lazio, Campania, Basilicata, Pugila e Calábria, têm o seu conselho legislativo, um executivo (junta regional) e um presidente. Segundo o artigo $117 .^{\circ}$ da Constituição, existe a autorização de legislar sobre um certo número de áreas ${ }^{20}$ (turismo, saúde, transportes).

Existem cento e dez províncias e oito mil e cento e três comuni-municípios.

\section{Processo de regionalização na Itália}

As cinco regiões com estatuto especial Vale d'Aosta, Friul-Venécia Juliana, Sardenha, Sicília e Trentino-Alto Adige são autónomas e semiautónomas devido às suas características étnicas ou geográficas especiais. Por esta razão têm poderes especiais concedidos ao abrigo da Constituição e assembleias regionais (semelhantes a parlamentos) e uma vasta gama de poderes administrativos e económicos.

\footnotetext{
${ }^{19}$ Como é o caso de Liga Lombarda da Lombardia.

${ }^{20}$ Esta transferência de competências é importante para a polícia local, trabalhos públicos, transportes, urbanismo, agricultura e turismo, saúde e assistência social.
} 
"A autonomia das outras 15 regiões italianas é reduzida. O poder legislativo das regiões rege-se pelo Título $\mathrm{V}$ da Constituição Italiana, que foi submetida a uma Reforma Constitucional em 2001”. “Em 2005, a Lei Nacional 11/2005 veio rever o processo italiano, permitindo ao Estado e às Regiões participarem na fase preparatória do processo de decisão da UE no domínio legislativo"21.

"Entre 1999 e 2001 ocorreram várias modificações constitucionais e leis de grande importância que reformaram muito sensivelmente as atribuições dos coletivos territoriais e dopado dos seus recursos financeiros". O novo artigo 114. ' da Constituição estipula: «A República é constituída pelos municípios, províncias, cidades metropolitanas, regiões e pelo Estado» a Constituição reconhece o princípio da subsidiariedade, tal como definido na Carta Europeia de Autonomia Local. A estrutura político-administrativa compreende três níveis ${ }^{22}: 20$ regiões, cento e três províncias e cerca de 8100 municípios.

O aparecimento de Ligas - Liga do Norte, com a figura de Umberto Bossi e Sicília (Sul) vieram a demonstram a instabilidade do governo italiano. A Liga do Norte nasceu da vontade de desenvolver a Itália para pedalar junto de uma União Europeia. Umberto Bossi ${ }^{23}$ proferiu em 1983 que tinha chegado a altura de transformar o Estado italiano numa confederação que respeita a identidade das diferenças etnias e o reconhecimento imediato da Lombardia como uma região com estatuto especial. A Liga do Norte foi importante no processo de descentralização. Ocorreu nessa altura a proposta de criação de três repúblicas: la Padaine, L'Etrurie, le Mezzogiorno.

\section{As diferenças entre as regiões italianas}

“Antes de incidir sobre as disparidades regionais na Itália é de relembrar que toda a União Europeia é um conjunto de diversidade de regiões. As regiões são organizadas institucionalmente no interior dos EMs, como unidades políticas cujas

21

http://cor.europa.eu/en/documentation/studies/Documents/Role\%20Regional\%20Parliaments\%20in\%20P rocess $\% 20$ of $\% 20$ Subsidiarity $\% 20$ Analysis $\% 20$ within $\% 20$ Early $\% 20$ Warning\%20System $\% 20$ of $\% 20$ Lisbo n\%20Treaty/PT.pdf p.55.

${ }^{22}$ Confira-se em: http://feader.rhone-

alpes.agriculture.gouv.fr/IMG/pdf/OrganisationTerritorialePaysEuropeens_cle077847.pdf Tradução feita pelo autor do trabalho.

${ }^{23}$ Umberto Bossi - Umberto Bossi - político italiano, que foi Deputado, Senador e também fez parte do Parlamento Europeu. 
autoridades são eleitas. Contudo as diferenças regionais e os diferentes" 24 estatutos das regiões no seio da UE entre os EMs são explicáveis (diferença entre Kreise alemão e as províncias italianas).

É de salientar que foram sobretudo as regiões que sofreram as reformas principais entre 1946 e 2001 recordemos as cinco de «estatuto especial» e as quinze.

A discussão Parlamentar e a figura de Romano Prodi ${ }^{25}$ (reformas públicas) veio questionar a salvaguarda da unidade da nação e a incerteza do que fazer. $\mathrm{O}$ argumento veio no sentido de uma regionalização que preserve o caráter unitário da nação ou uma transformação federal da sua Constituição. Em 1996 foi feita a reforma federal, um projeto de lei - alargamento das competências das regiões e dos coletivos locais, reforma da administração pública e de simplificação dos procedimentos administrativos. As instituições italianas passaram a ser "quase" federais, Prodi definiu limitativamente as funções confiadas ao Estado central: relações externas, defesa, imigração.

O propósito passaria por aumentar e desenvolver as margens de autonomia financeira e fiscal das regiões em três anos. A comissão bicameral ficou encarregue de preparar um projeto de revisão da Constituição - a terminar em 1997. O curso de reforma das administrações locais apareceu da vontade de modernizar os sistemas administrativos nacionais e de resistir contra certas tendências centralizadoras.

Não se prevê concluir num limite de tempo um dos pontos de elevada relevância da política da União Europeia, por isso será apresentada, uma reflexão. A Política Regional foi o Passado que resultou nos cenários que vemos hoje. Mas sobretudo será o Futuro dos investimentos e das atenções que hoje plantarmos. A União Europeia tem- se preocupado realmente no investimento e no acompanhamento dos resultados das suas práticas. Falta a compreensão e a informação das possibilidades das regiões no contexto europeu. Diria- se, transparência. A Comissão Europeia e o Comité das Regiões são os "refúgios" máximos da população local. Com isto quer- se dizer que o papel importante está nos cidadãos que, membros do Comité, das Assembleias das Regiões e municípios percebam e vão ao encontros das dificuldades numa escala ascendente. Pois quem está nos edifícios espelhados de Bruxelas nem sempre se apercebe do que está a falhar e do que é, realmente, necessário para combater as lacunas. Pergunta- se, porque é que a Europa interessa às regiões e qual a importância das regiões na União Europeia? Por

\footnotetext{
${ }^{24}$ Tradução feita pelo autor do trabalho, de KUKAWKA, Pierre (2001) L'Europe par les régions, Presses Universitaires de Grenoble. p.10.

${ }^{25}$ Romano Prodi- Figura política importante não só na Itália. Foi Primeiro-ministro da Itália 1996 - 1998 e 2006 - 2008; Presidente da Comissão Europeia 1999 - 2004.
} 
três motivos que foram de uma forma ou de outra referidos ao longo da abordagem acima mas que mesmo assim importa salientar. Primeiro, as regiões são "micro uniões europeias" mas, que estão perto dos cidadãos e essa é a forma mais fácil de se conhecer a Europa e de agarrar as oportunidades que visam o desenvolvimento dessas regiões; Em segundo lugar, as regiões, no caso italiano isso também é visível possuem direta ou indiretamente de uma voz que os faz ouvir nas Instituições, essa voz é o CR. Em último, mas não menos importante é a localização das regiões e a possibilidade da sua cooperação dentro do país bem como a fora fronteiras. Seja através da cooperação transfronteiriça seja numa cooperação indireta, através dos Fóruns regionais, germinações. Por estas e mais razões é necessário desenvolver uma cooperação mais estreita entre os Parlamentos nacionais e as Assembleias regionais.

A uma escala mais interna dos próprios fundos estruturais da UE salienta-se a importância da cooperação inter-regional INTERREG C. Do programa cooperação inter-regional são de ressalvar os objetivos das políticas e instrumentos de desenvolvimento regional através da troca de informações em larga escala e a partilha de experiências (redes). A cooperação transfronteiriça e principalmente as regiões fronteiriças são, acima de tudo, a troca de ideias, as informações e resoluções de problemas. Temos de ter em contas que as regiões, apesar de todas pertencerem à União Europeia e aqui também, as regiões ultraperiféricas, estas, tal como as regiões continentais europeias (que não ultraperiféricas) possuem especificidades no que diz respeito ao clima, geografia, economia e cultura. Diferenças às quais é precisos saber responder.

A regionalização tem que ser vista como um fenómeno cada vez mais presente e evidente na União Europeia. Itália de Piemonte e de Prodi em muito contribuíram para a administração que se encontra hoje no território italiano. Espera-se que a desordem política na Itália não faça e a União Europeia não permita, com que as ideias de desenvolvimento e progresso regional "fuja pelo sapato" com medo de uma descentralização europeia que poderá dar origem à impossibilidade de controlo de todo o território. E tem de se continuar a investir nele. Ou a questão poderá colocar-se de seguinte forma: Será que "os nacionalismos regionais na Europa” poderão constituir um receio da Europa, na sua subdivisão ao invés de uma união cada vez mais visível? O desejo de afirmação regional passa, também, pelos aspetos culturais. Poderá a União transformar- se em "muitas outras" Flandre(s) e Valónia(as) com os problemas de 
regionalização linguística: Países Basco(s), Irlanda(s) e perder o rumo da "cidadania europeia"? Lança- se a reflexão.

\section{Fontes:}

Relatórios - Fundos Estruturais

http://cor.europa.eu/en/documentation/studies/Documents/Role\%20Regional\%20Parlia ments\%20in\%20Process\%20of\%20Subsidiarity\%20Analysis\%20within\%20Early\%20 Warning\%20System\%20of\%20Lisbon\%20Treaty/PT.pdf http://www.politichecomunitarie.it/banche-dati/17187/beneficiari-fondi-europei-regioni

\section{Bibliografia:}

PASQUICCINI, Daniele, «De la périphérie au centre: les regiones italiennes et l'intégration eurupeenne» in AMARAL, Carlos E. Pacheco /ed (2011) Autonomie régionale et relations internationales - Nouvelles Dimensions de la Gouvernance Multilatérale. Paris, Colecção «Inter- National» L'Harmattan.

PASQUICCINI, Daniele, «L'Etat «régionalisé»:le modele italien» in DEYON, Pierre (1997) Régionalismes et régions ans l' Europe des quinze, France, Bruylant.

KUKAWKA, Pierre (2001) L'Europe par les régions, Presses Universitaires de Grenoble.

Hérodote revue de géographie et de géopolitique $4^{\circ}$ trimestre N. ${ }^{\circ 95} 115$

F LACOSTE, Yves, (1999) Nationalismes Régiounaux en Europe, Paris: La Découverte.

\section{Sites consultados:}

Site oficial do Comité das Regiões http://cor.europa.eu/pt/Pages/home.aspx Site oficial da Política Regional http://ec.europa.eu/regional_policy/index_pt.cfm http://ec.europa.eu/regional_policy/index_pt.cfm 
http://ec.europa.eu/europe2020/europe-2020-in-a-nutshell/targets/index_pt.htm

http://www.twinning.org/pt/page/enquadramento-breve.html Última consulta em 29.12.2013.

http://europa.eu/legislation_summaries/regional_policy/index_pt.htm Última consulta em 01.01.2014.

http://europa.eu/pol/reg/index_pt.htm Última consulta em 01.01.2014.

Site da Assembleia da UE dos representantes regionais e locais http://cor.europa.eu/pt/Pages/home.aspx Última consulta em 03.01.2014.

http://www.twinning.org/pt/page/o-conselho-dos-munic\%C3\%ADpios-eregi\%C3\%B5es-da-europa.html Última consulta em 03.01.2014.

http://www.iscsp.utl.pt/ cepp/teoria_das_relacoes_internacionais/a_jovem_europa_de_ mazzini.htm Última consulta em 03.01.2014.

http://www.sedep.com.br/?idcanal=25175 Última consulta em 03.01.2014.

http://www.igfse.pt/upload/docs/2013/comofuncionaaUE.pdf Última consulta em 03.01.2014.

http://feader.rhonealpes.agriculture.gouv.fr/IMG/pdf/OrganisationTerritorialePaysEurop eens_cle077847.pdf Última consulta em 03.01.2014. 